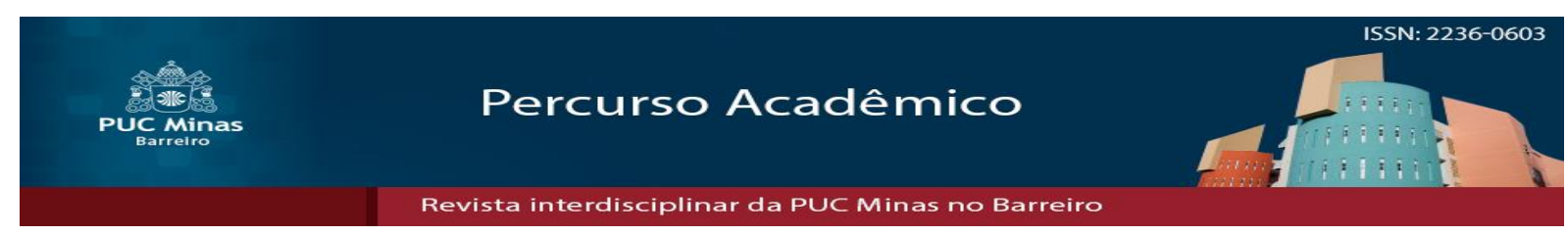

\title{
Avaliação de viabilidade técnica para incorporação dos resíduos da construção civil em obras de pavimentação
}

\section{Technical feasibility assessment for the incorporation of construction waste into paving Works}

\section{Resumo}

Mateus Bravo de Aguiar $^{1}$ Francine Martins Alves ${ }^{2}$ Milene Gabriela Gomes ${ }^{3}$ Laura Francis Porto ${ }^{4}$ Laerson Felipe Ribeiro Gomes ${ }^{5}$ Prof. Dra. Raquel Sampaio Jacob ${ }^{6}$

A destinação apropriada dos rejeitos constitui um grande desafio, principalmente no que se refere aos resíduos de construção e demolição (RCD). Dessa forma, o presente trabalho tem como objetivo geral, o estudo dos parâmetros físicos dos RCD's retirados na Usina de Reciclagem e Entulho da Pampulha em Belo Horizonte, com a finalidade de estudar sua resistência para que seja utilizado em obras de pavimentação. Para tanto, foi feito um estudo de modo a avaliar a viabilidade técnica, financeira e ambiental desse material. Com o propósito de o material ser aprovado, comparou-se com o solo-argila fornecido pelo laboratório de ensaios e campo da (PUC Minas)- Campus Coração Eucarístico. Foram realizados ensaios de granulometria, compactação para determinação da massa específica aparente seca e umidade ótima, Índice de Suporte Califórnia (CBR) e expansão, utilizando-se 50\% de RCD mais 50\% de solo-argila e $100 \%$ de RCD, visando atestar a qualidade do produto em estudo. Tais testes seguiram as recomendações da Associação Brasileira de Normas Técnicas (ABNT). Constatou-se que o material adquirido na usina (agregado reciclado) apresentou uma boa resistência comparando-se os ensaios realizados com $100 \%$ de RCD e 50\% RCD com 50\% solo-argila doado pelo Laboratório da PUC Minas Campus Coração Eucarístico.

Palavras-chave: Pavimentação, resíduo de construção civil, Índice de suporte Califórnia.

\begin{abstract}
The appropriate disposal is a big challenge, particularly when it comes to construction and demolition waste (CDW). This way, this research has as a main purpose; the study of physical and economic parameters of CDW's obtained from the recycling and debris plant in Pampulha, Belo Horizonte, for the purpose of using such material for the construction of sub-grade and sub-base support in paving works. Besides that, a study was carried out to evaluate the financial, technical and environmental viability for this material. Willing the approval of the material, the clay provided by the laboratory of testing and field at the campus of Coração Eucarístico, (PUC Minas). Granulometry and compaction tests were made in order to certify the specific wet apparent mass and greater humidity, California Bearing Ratio (CBR) and expansion, using $50 \%$ of CDW plus $50 \%$ of soil-clay and $100 \%$ of CDW, looking for quality
\end{abstract}

Artigo recebido em 07 de Julho de 2017 e aprovado em 29 de Março de 2019.

${ }^{1}$ Graduado na Pontifícia Universidade Católica de Minas Gerais (PUC MINAS), Brasil. E-mail: mateus.aguiar@sga.pucminas.br ${ }^{2}$ Graduada na Pontifícia Universidade Católica de Minas Gerais (PUC MINAS), Brasil. E-mail: francine_martinsa@hotmail.com 3 Graduada na Pontifícia Universidade Católica de Minas Gerais (PUC MINAS), Brasil. E-mail: milenegomes0502@gmail.com 4 Graduada na Pontifícia Universidade Católica de Minas Gerais (PUC MINAS), Brasil. E-mail: lauracml211@gmail.com 5 Graduado na Pontifícia Universidade Católica de Minas Gerais (PUC MINAS), Brasil. E-mail: laersonfelipe@gmail.com ${ }^{6}$ Doutora Mestre e em Saneamento, Meio Ambiente e Recursos Hídricos pela Escola de Engenharia da Universidade Federal de Minas Gerais (UFMG), Especialista em Saneamento e Meio Ambiente pela Escola de Engenharia da UFMG, na área de Controle Ambiental na Indústria, Graduada em Ciências Biológicas pela Pontifícia Universidade Católica de Minas Gerais (PUC MINAS). É Professora Adjunto I da Pontifícia Universidade Católica de Minas Gerais, Brasil. E-mail: sampaiojacob@gmail.com 
certification for the studied product. These theses are according to the "Associação Brasileira de Normas Técnicas (ABNT)" recommendations. We found out that the material (crusher run aggregation) presented a good resistance when compared with the $100 \%$ of CDW and $50 \% \mathrm{CDW}$ with $50 \%$ soil-clay come from the Coração Eucaristico Campus.

Keywords: Paving. Construction waste. California Bearing Rati.

\section{Introdução}

A construção civil tem crescido rapidamente e tem sido uma das atividades que mais contribui para a deterioração dos ecossistemas, polui o meio ambiente e gera resíduo. Com esse crescimento desenfreado e sem a preocupação em preservar o meio ambiente e seus recursos naturais, surgiu-se a necessidade de implantar o desenvolvimento sustentável na construção civil. (MINISTÉRIO DO MEIO AMBIENTE, 2013).

O conceito de desenvolvimento sustentável na construção civil entende-se como um método que apresenta alternativas na utilização de recursos, na orientação aos investimentos, na direção ao crescimento tecnológico e nas transformações empresariais, todos tendo em vista o equilíbrio e o vínculo nos interesses e a utilidade no presente e no futuro. Esta concepção não inclui apenas disciplina, abrange também transformações culturais, educação, ecossistêmica e olhar sistêmico. (ÂNGULO; ZORDAN; JOHN, 2010).

Por meio da compreensão de que os insumos oriundos de matérias primas são termináveis novas pesquisas para a evolução de novas técnicas e insumos que contribuam na conservação dessas matérias são cada vez mais aperfeiçoados. (SPADOTTO et al., 2011).

Segundo a Associação Brasileira de Reciclagem de Resíduos para a Construção Civil e Demolição (2015), o progresso e evolução dos centros urbanos transportam para toda a sociedade uma adversidade que não pode ser oculta, sendo a geração de Resíduos Sólidos. Nos municípios brasileiros de médio e grande porte os resíduos oriundos de construções e demolições constituem de $40 \%$ a 70 \% de todos os resíduos sólidos deste município, dos quais a destinação incorreta gera detrimentos sociais, econômicos e 
ambientais. O Brasil apresenta uma produção média anual de $500 \mathrm{~kg} / \mathrm{hab}$ de RCD, estima-se que a produção total anual seja de 84.180 .696 m3.

Diante deste contexto, surgem novos métodos e materiais sustentáveis que podem ser formados com a adição de RCD (Resíduos de construção e demolição) em sua composição, criando-se assim maneiras de reaproveitar esse tipo de resíduo para outros fins. Com foco nestes paradigmas sustentáveis, alguns órgãos ambientais, construtoras e a sociedade buscam soluções "verdes" para construir, reduzindo a emissão de gases poluentes na atmosfera e diminuindo os resíduos gerados na construção, desta forma buscando o desenvolvimento sustentável e o bem-estar social, minimizando os impactos sobre o meio ambiente. (PINTO, 1999).

Após passar o RCD por um procedimento de reciclagem, pode ser utilizado em diversas áreas, como na elaboração de elementos pré-moldados e na realização de camadas em estruturas de pavimentos. Na Holanda, por exemplo, 85\% dos resíduos de construção civil são submetidos a um processo de beneficiamento para serem utilizados nestas duas finalidades citadas acima. Com isso, umas das alternativas para os RCD’s é sua utilização em camadas de pavimentos após ser submetido ao processo da reciclagem, vindo a gerar o agregado reciclado. (HENDRIKS; JANSSEN, 2001).

De acordo com Leite (2007), a responsabilidade com impacto ambiental e com a destinação adequada para o grande volume de resíduos sólidos gerados pela construção civil possibilita os estudos no campo de reciclagem destes resíduos. A utilização do agregado reaproveitado na pavimentação tem os seguintes benefícios:

a) Redução dos custos com pavimentação, uma vez que estarão substituindo os recursos naturais;

b) Redução de gastos com transporte de materiais de empréstimos;

c) Redução dos custos com as atividades dos aterros sanitários, uma vez que receberá uma quantidade menor de resíduos;

d) Utilização de áreas menores para a continuidade dos aterros sanitários, devido à diminuição do RCD;

e) Melhoramento das situações de saneamento das cidades;

f) Redução de gastos com limpeza urbana;

g) Racionamento de jazidas minerais naturais, junto a diminuição de exploração das mesmas, resultando na redução da agressividade causada ao meio ambiente. 
Aguarda-se que com a conclusão obtida desta pesquisa, seja incentivado o reaproveitamento do resíduo gerado na construção civil sempre que possível, para substituir material natural não reaproveitado, como britas graduadas e materiais consolidados granulométricos e a redução do transporte com materiais em áreas de empréstimo. Reutilizando-se o resíduo gerado pela a construção civil na composição de subleito, sub-base e base de pavimentação.

\section{Materiais e métodos}

Conforme já mencionado, foi-se analisados os parâmetros granulométricos, umidade ótima, Índice de Suporte Califórnia (CBR) e expansão, por meio dos testes laboratoriais com 8 corpos de provas (Cp's), sendo 5 corpos de provas confeccionados com 100\% de resíduos da construção civil (agregado reciclado) e 3 corpos de provas confeccionados com 50\% materiais convencionais (solo-argila) e 50\% de resíduos da construção civil (agregado reciclado). Após os testes, foram avaliadas as vantagens e desvantagens do uso dos resíduos sólidos da construção civil para confecção de subleito, sub-base e base de pavimentação, levando em consideração sua contribuição para o meio ambiente.

Ao realizar pesquisas bibliográficas, verificou-se que a Construção Civil gera toneladas de resíduos diariamente, e que podem ser reaproveitados na área de Engenharia Civil, após serem processados em uma Usina (Figura 1). 


\section{Figura 1 - Formação do agregado reciclado}

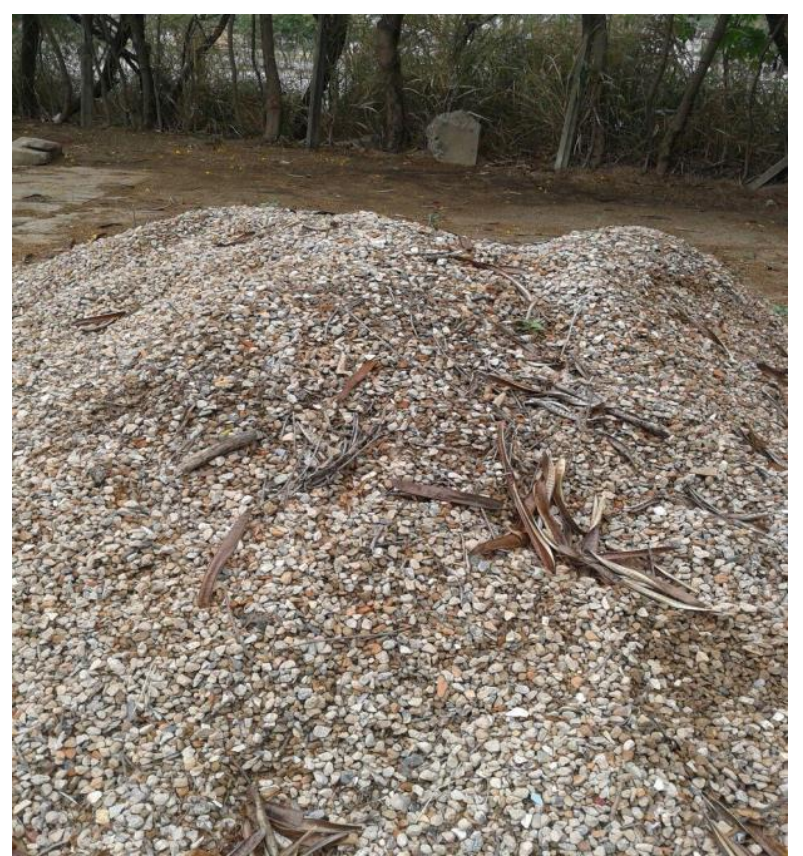

Fonte: Fotografia dos autores.

\section{1-Ensaios laboratoriais}

Foram realizados os ensaios de Compactação e CBR no laboratório de Mecânica dos Solos da Pontifícia Universidade Católica de Minas Gerais, no Campus Coração Eucarísticos, em Belo Horizonte.

Para realização dos referidos ensaios, serão utilizados os equipamentos estufa de secagem, cápsulas, extensômetros e prensa CBR, tanque, cilindro Proctor, a partir dos quais se realizam os seguintes testes: Teor de umidade, Compactação e CBR.

As normas que foram consultadas para realização dos ensaios são:

a) Teor de Umidade - NBR 6457/1984;

b) Compactação NBR 7182/1986;

c) CBR - DNIT 172/2016.

No laboratório de solos da PUC Minas Coração Eucarístico, iniciaram-se as primeiras etapas para realização dos Ensaios de Compactação, CBR e Índices Físicos. 
Foram transportados para o Laboratório 106,1 Quilos de Resíduos da Construção Civil retirados da Usina SLU - Usina de reciclagem da Pampulha em Belo Horizonte. Inicialmente, foi realizada a separação dos materiais, passando-o a peneira vibratória, separando os grãos finos dos grossos, como mostra na figura 2. Para a realização dos ensaios foram utilizados somente os grãos finos.

Figura 2 - Peneiramento do RCD

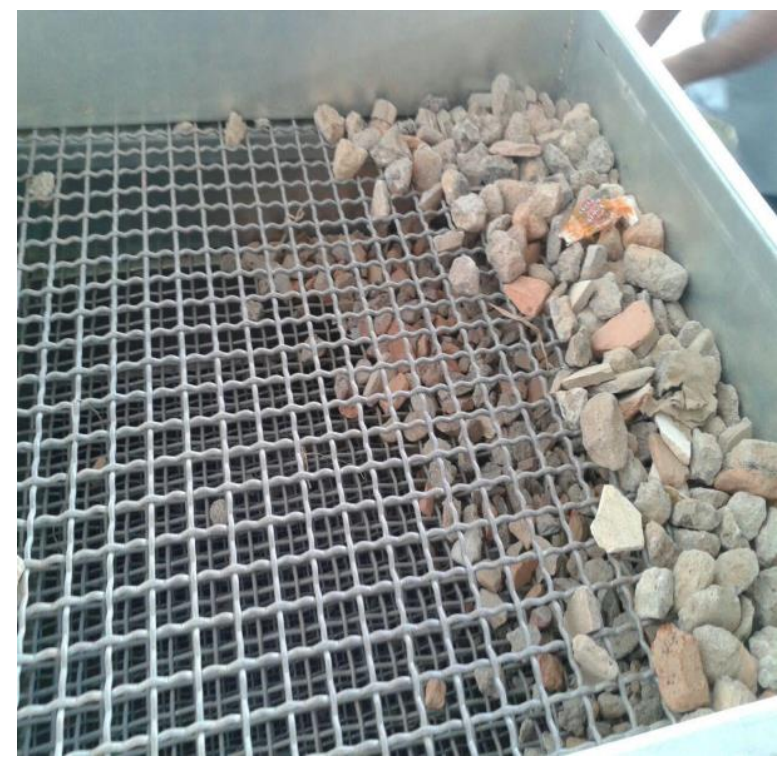

Fonte: Fotografia dos autores.

\subsection{1-Determinação do teor de umidade}

No montante de 50,9 Quilos de grãos finos, foram retirados aproximadamente 100 gramas de amostra para determinação do teor de umidade no método empírico.

Este método foi realizado da seguinte forma: foram separados 50,9 quilos de solos finos e adicionado água em pequenas quantidades, então, o solo é esmagado na palma da mão formando torrões de terra, como mostra na figura 3, que ao serem soltos no chão de uma altura 0,5 metros, os torrões se "desmancham". Empiricamente, quando isso acontece,o material fica próximo da umidade ótima. (ABNT NBR 9895:1987), ou seja, no nível crítico de umidade. 


\section{Figura 3 - Formação dos torrões}

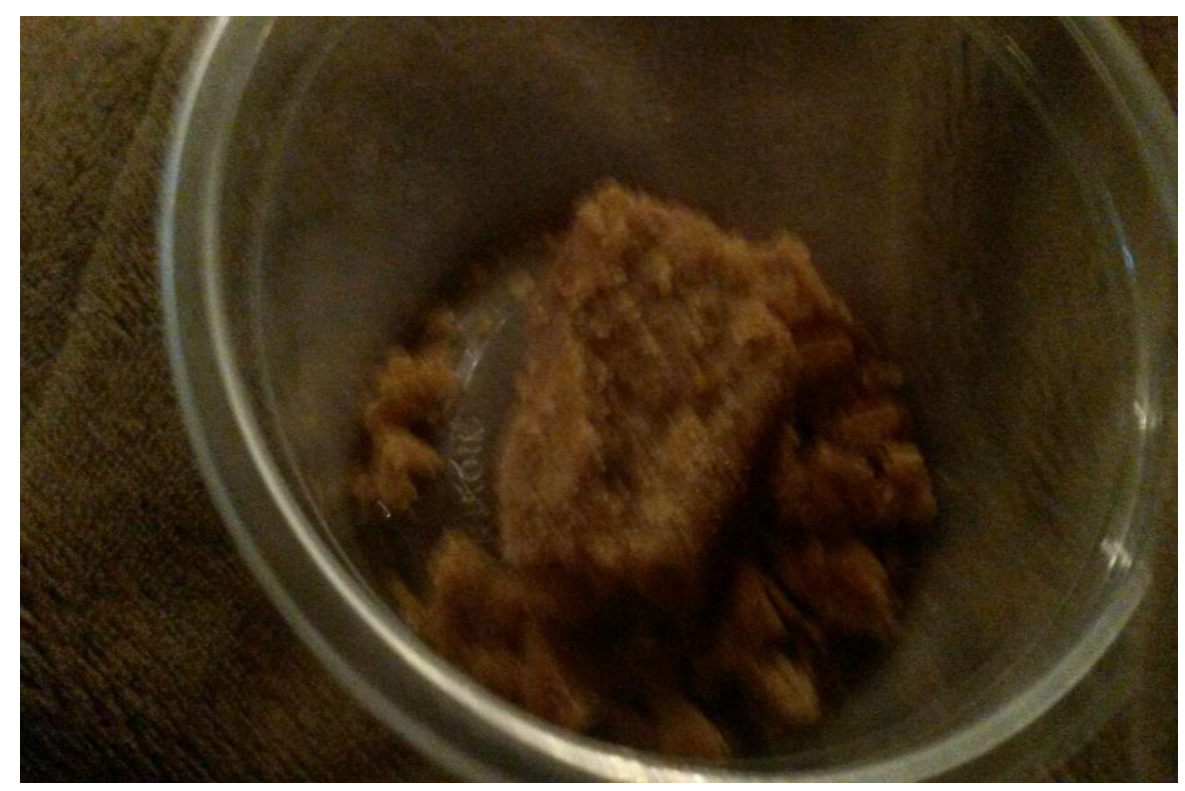

Fonte: Fotografia dos autores.

Posteriormente, com os solos finos umedecidos, atingindo um teor de umidade próximo da ótima, retiram-se amostras para 03 cápsulas, que foram secas em uma estufa, mostrado na Figura 4, até ficarem totalmente secas, onde se obteve o teor de umidade de acordo com a equação 1 (ABNT NBR 6457:1986). 


\section{Figura 4 - Secagem das amostras}

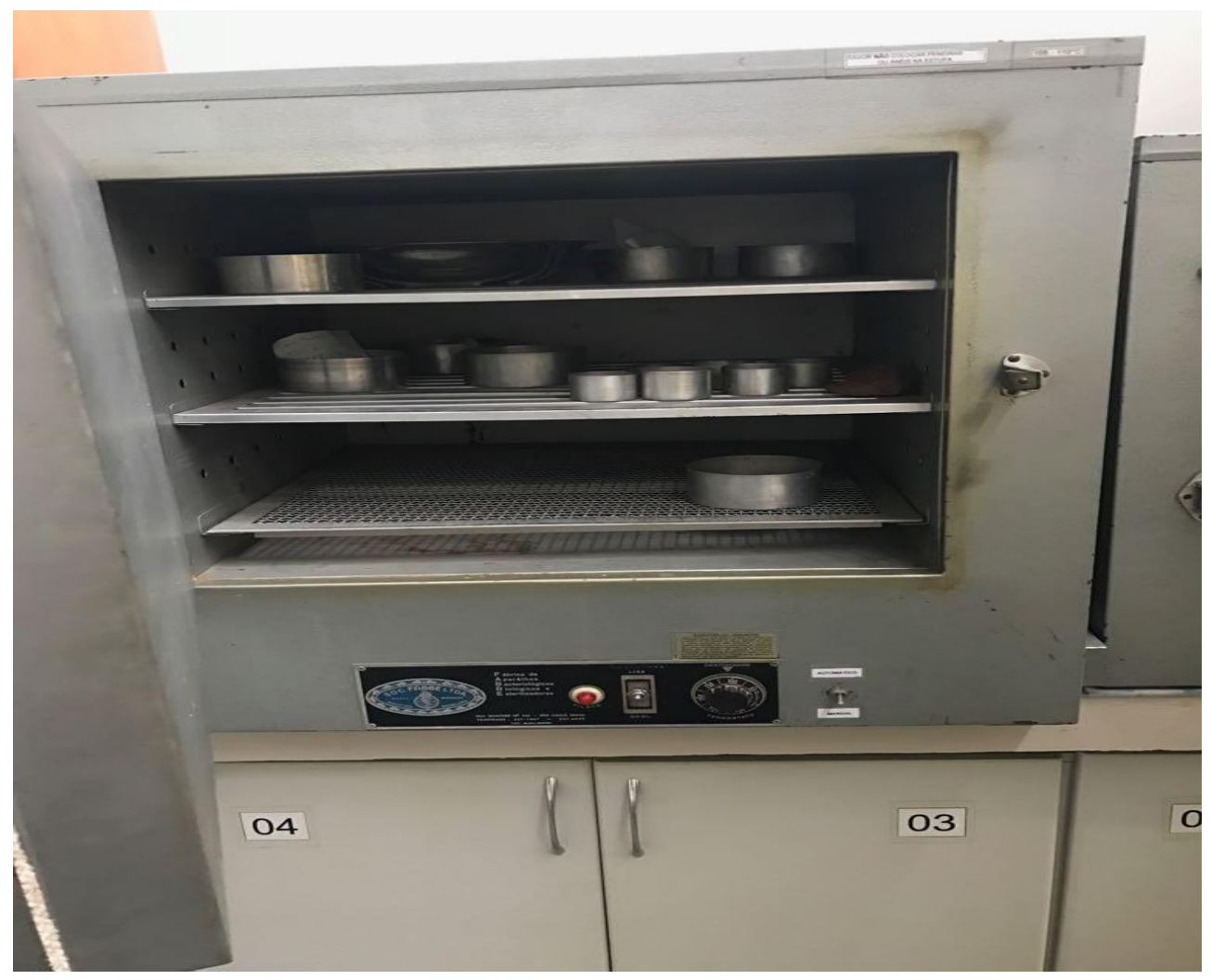

Fonte: Fotografia dos autores.

Equação 1 (COMPACTAÇÃO, 2012):

$$
h=\frac{P-P S}{P S} \times 100
$$

Onde:

a) $\mathrm{h}=$ Teor de umidade em $\%$;

b) $\mathrm{P}=$ Peso úmido da amostra;

c) $\mathrm{Ps}=$ Peso seco da amostra.

\subsection{2-Ensaio de compactação}

Em paralelo a este ensaio, começou-se o ensaio de compactação dos corpos de prova. No primeiro dia de ensaio, moldaram-se 05 (cinco) corpos de prova com $100 \%$ RCD, no segundo dia foram moldados 03 (três) corpos de prova $50 \%$ de RCD e $50 \%$ de solo-argila, disponibilizados pelo laboratório de ensaio e campo da PUC - Coração Eucarístico (Figura 5) para que fossem executadas as duas proporções nos ensaios de compactação e posteriormente de CBR. (ABNT NBR 6457:1986). 


\section{Figura 5 - Separação das proporções de amostra}

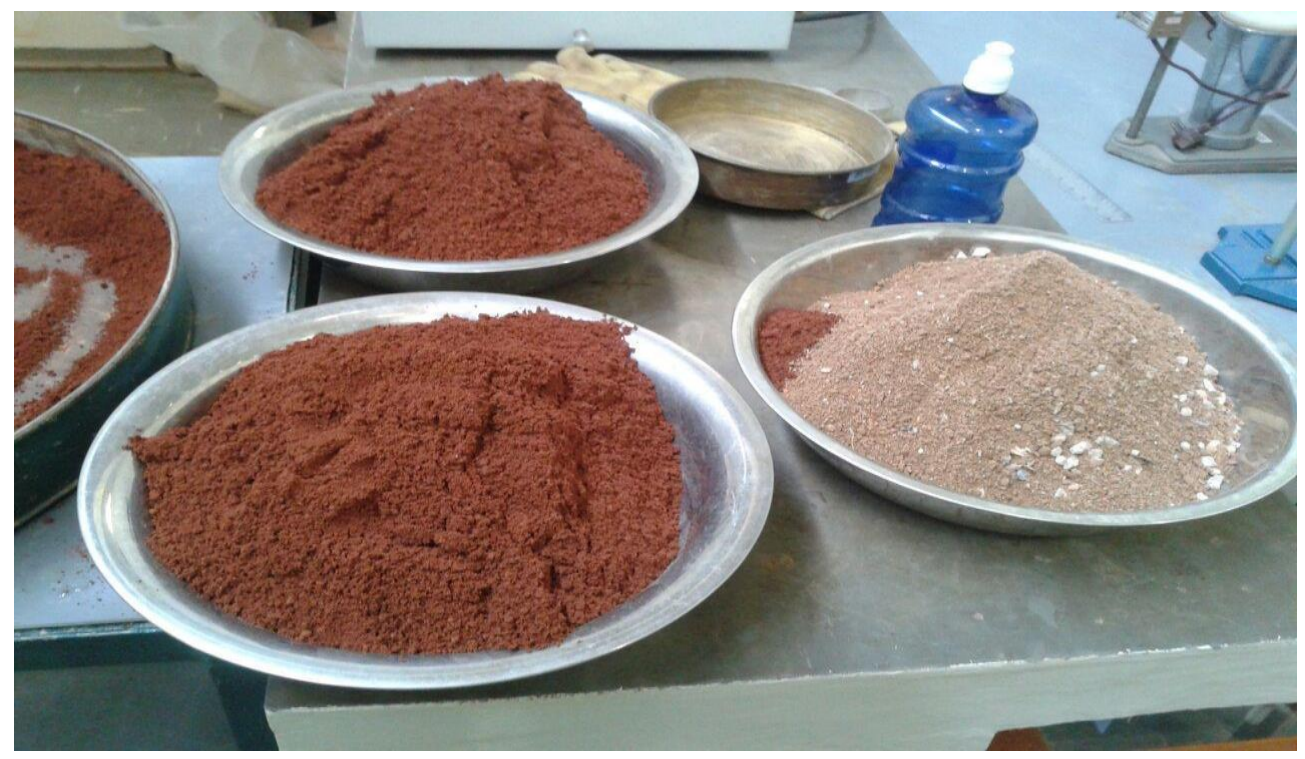

Fonte: Fotografia dos autores.

No ensaio de compactação, foi adicionada água nas proporções de $2 \%, 4 \%$ e $6 \%$ nos corpos de prova. O material logo em sequência foi homogeneizado para ser destinado ao cilindro de Proctor modificado, para a realização dos testes (ABNT NBR 9895:1987).

Foi compactado em 5 camadas com 12 golpes de soquete em cada camada de acordo com a figura 6 (ABNT NBR 9895:1987).

\section{Figura 6 - Ensaio Proctor}

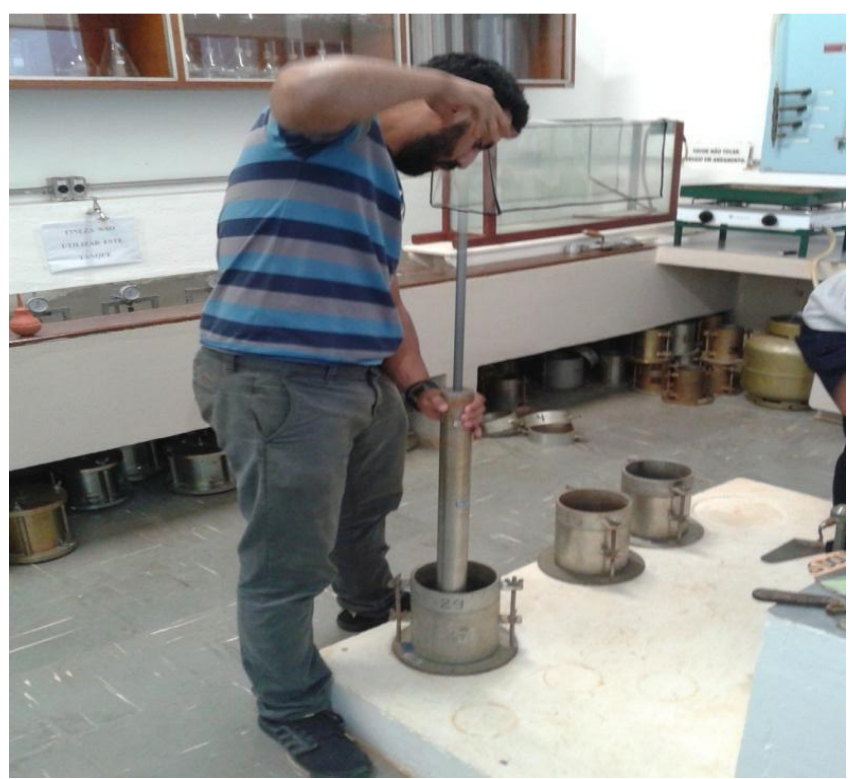

Fonte: Fotografia dos autores. 
Após o fim do ensaio de compactação, os CP's ficaram submersos em um tanque (Figura 7) num período de quatro dias, para ficarem saturados e simularem a situação crítica em campo, onde por meio de um extensômetro mediu-se a expansão/ recalque do CP compactado. (MOURA R. F., 2015).

Para o cálculo da expansão (\%), usa-se a equação 2:

Equação 2 (COMPACTAÇÃO, 2012):

$$
E=\frac{(h-h i)}{h i} \times 100
$$

Onde:

a) (h - hi): Deformação até o instante considerado;

b) hi: Altura inicial do corpo de prova.

Figura 7 - Imersão dos Corpos de prova

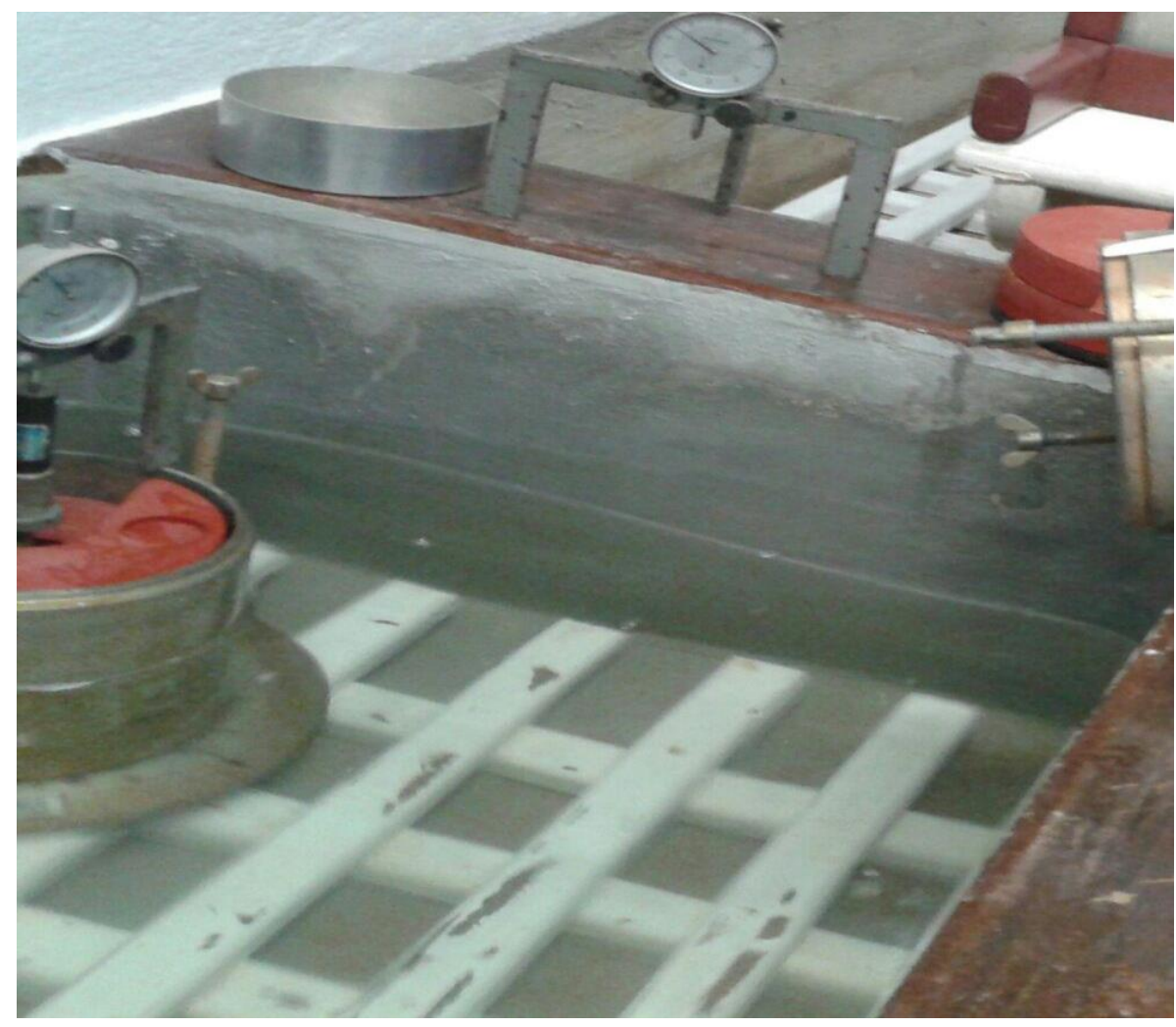

Fonte: Fotografia dos autores. 


\subsection{3-Ensaio do CBR}

Finalmente, realizou-se o ensaio de CBR (Figura 8), que consiste na determinação da relação entre a resistência à penetração de uma amostra do solo saturado, compactado e a resistência à penetração de uma brita graduada, adotada como padrão de referência. Tal padrão pode ser analisado de acordo a Tab 1 (ABNT NBR 9895:1987).

\section{Figura 8 - Ensaio de CBR}

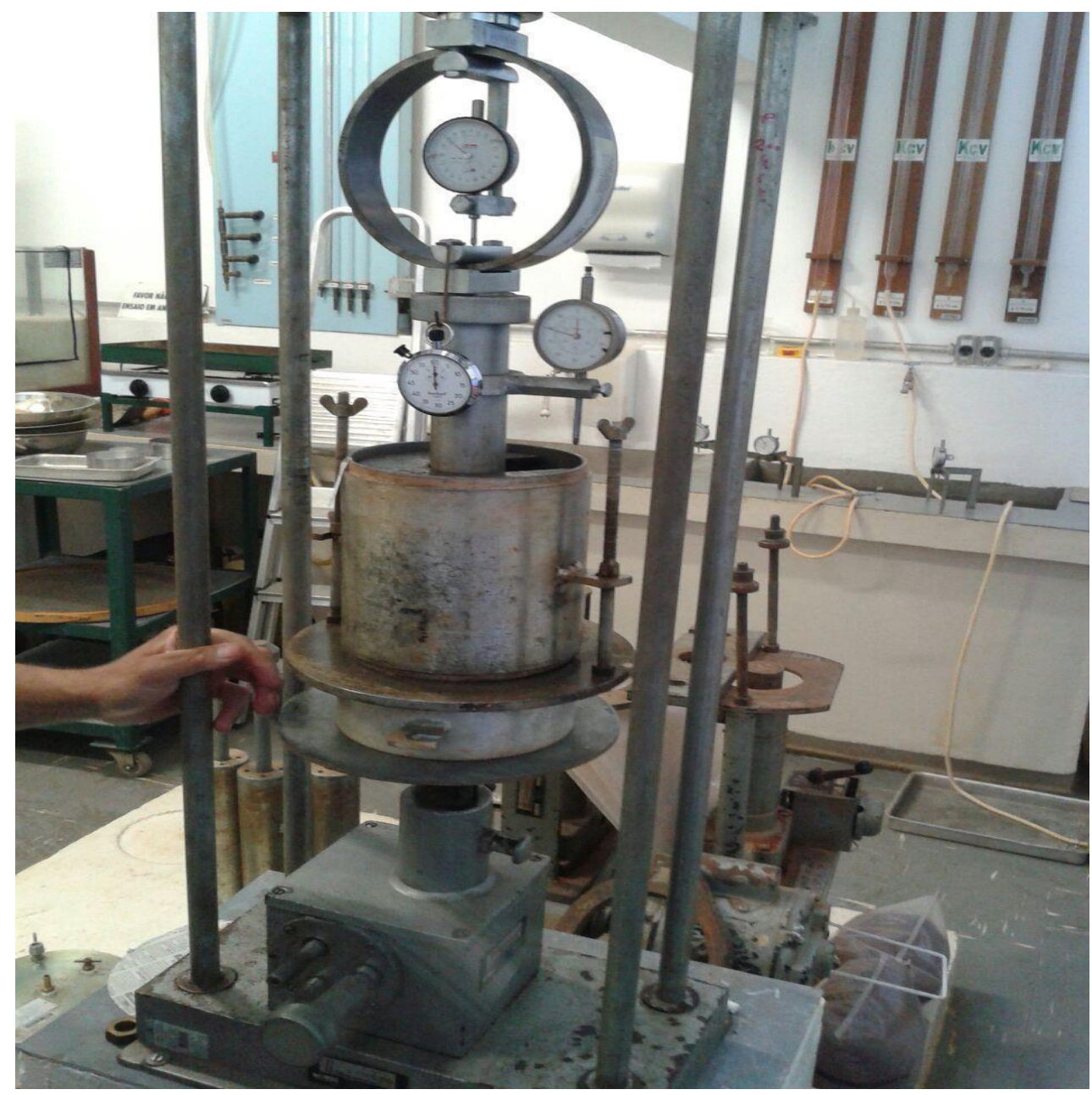

Fonte: Fotografia dos autores. 
Tabela 1 - Padrão de referência do CBR

\begin{tabular}{|c|c|c|c|}
\hline \multirow{2}{*}{$\begin{array}{l}\text { TEMPO EM } \\
\text { MINUTOS }\end{array}$} & \multicolumn{2}{|c|}{ PENETRAÇÃO } & \multirow{2}{*}{$\begin{array}{l}\text { PRESSÃO } \\
\text { PADRÃO } \\
\mathrm{Kg} / \mathrm{MC}^{2}\end{array}$} \\
\hline & $\mathrm{mm}$ & pol. & \\
\hline 0,5 & 10,00 & 0,025 & - \\
\hline 1,0 & 1,27 & 0,050 & - \\
\hline 1,5 & 1,90 & 0,075 & - \\
\hline 2,0 & 2,54 & 0,100 & 70 \\
\hline 3,0 & 3,81 & 0,150 & - \\
\hline 4,0 & 5,08 & 0,200 & 105 \\
\hline 6,0 & 7,62 & 0,300 & 132 \\
\hline 8,0 & 10,16 & 0,400 & 161 \\
\hline 10,0 & 12,70 & 0,500 & 182 \\
\hline
\end{tabular}

Fonte: Elaborado pelos autores.

Para a execução do cálculo de CBR, determina-se o maior valor das leituras de cargas obtidas nas penetrações $2,54 \mathrm{~mm}$ ou $5,08 \mathrm{~mm}$ de acordo com a equação 3. (ABNT NBR 9895:1987).

Equação 3:

$$
C B R=\frac{\text { maior pressão lida ou corrigida }}{\text { pressão padrão }} \times 100
$$

A partir dos ensaios citados acima, será realizada a comparação dos materiais solo argila disponibilizado pelo laboratório de Ensaio e Campo da PUC - Coração Eucarístico e o resíduo coletado na Usina de reciclagem da Pampulha, para avaliar a utilização dos referidos materiais na execução de subleito, sub-base e base de pavimentação. 


\section{Resultados e discussões}

Neste capítulo serão apresentadas as análises de caracterização física, Compactação e CBR. Compreendem os ensaios laboratoriais realizados com a amostra de agregado reciclado coletado na Usina de Reciclagem na Pampulha e o material soloargila fornecido pelo laboratório, sendo um material padrão para simular o solo.

\section{1- Caracterização dos resíduos}

Para a realização do ensaio granulométrico foi utilizado o método de agitação mecânica por meio de peneiras vibratórias de malhas quadradas. Logo após o peneiramento foi realizada a pesagem do material retido em cada peneira e realizada a soma de todas as parcelas retidas para a obtenção da quantidade de solos finos conforme se verifica na Tab 2.

Após passar o material na peneira vibratória, obteve-se o somatório de aproximadamente 50,9 quilos de solos finos, considerados para os estudos. O peso de aproximadamente 55,2 quilos de grãos grossos retidos na peneira foi descartado.

Tabela 2 - Separação Granulométrica

\begin{tabular}{|c|c|c|}
\hline Peneira & Bitola & Retido \\
\hline 4 & 4,75 & $6,0 \mathrm{~kg}$ \\
\hline $1 / 4$ & 6,35 & $5,8 \mathrm{~kg}$ \\
\hline $3 / 8$ & 9,52 & 14,7 kg \\
\hline $3 / 4$ & 19 & $28,7 \mathrm{~kg}$ \\
\hline \multicolumn{2}{|c|}{ Solo Fundo } & $50,9 \mathrm{~kg}$ \\
\hline \multicolumn{2}{|c|}{ Peso total } & $106,1 \mathrm{~kg}$ \\
\hline
\end{tabular}

Fonte: Elaborado pelos autores.

\section{1- Determinação do teor de umidade}

Após o ensaio de compactação de 5 corpos de prova utilizados com 100\% de RCD, obteve um teor de umidade ótima $6 \%$ através da curva de compactação (Figura 
9). Durante o ensaio, o quinto corpo de prova foi descartado por estar completamente saturado e por não possuir resistência devido a sua saturação.

Já os ensaios com 50\% de RCD foram realizados com 3 corpos de provas e obteve-se um teor de umidade ótima de $4 \%$ conforme a figura 10 pela curva de compactação.

Figura 9 - Resultados dos ensaios de compactação com $100 \%$ de RCD

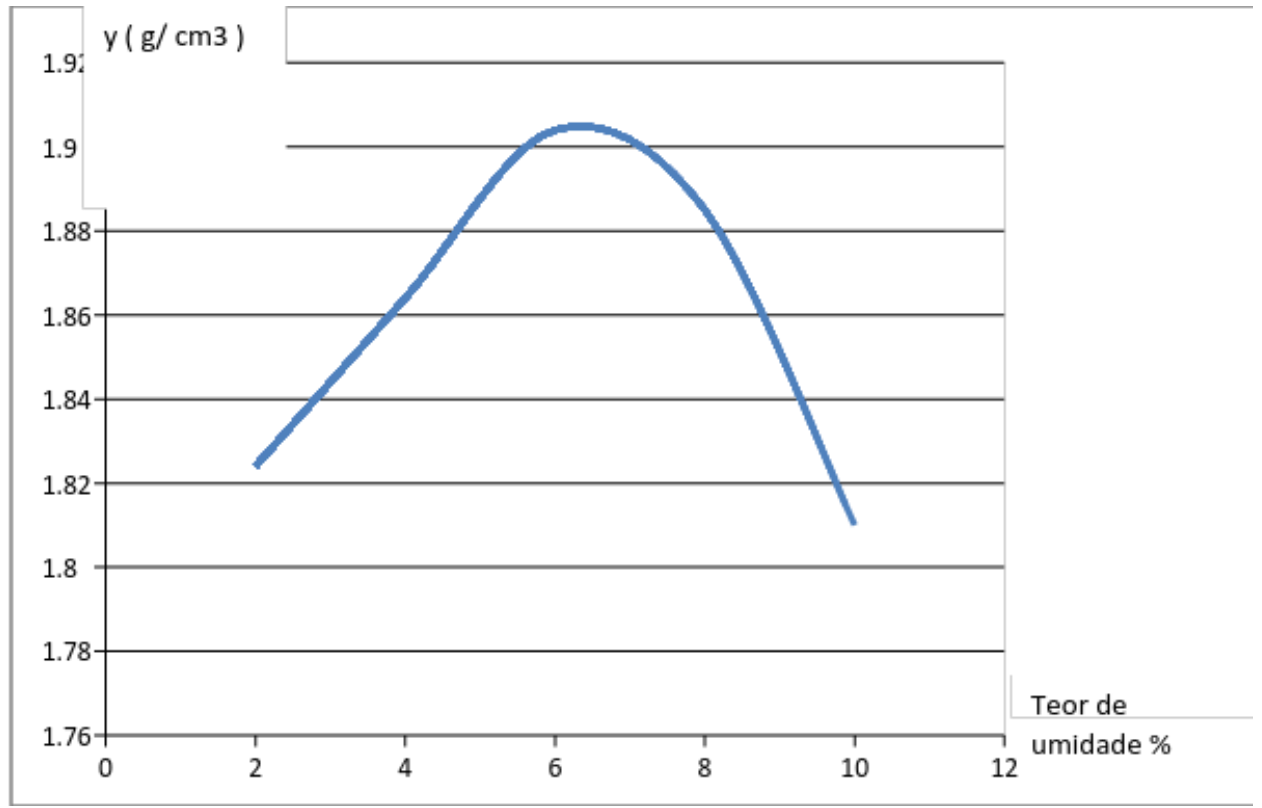

Fonte: Elaborado pelos autores.

Figura - Resultados dos ensaios de compactação com 50\% de RCD

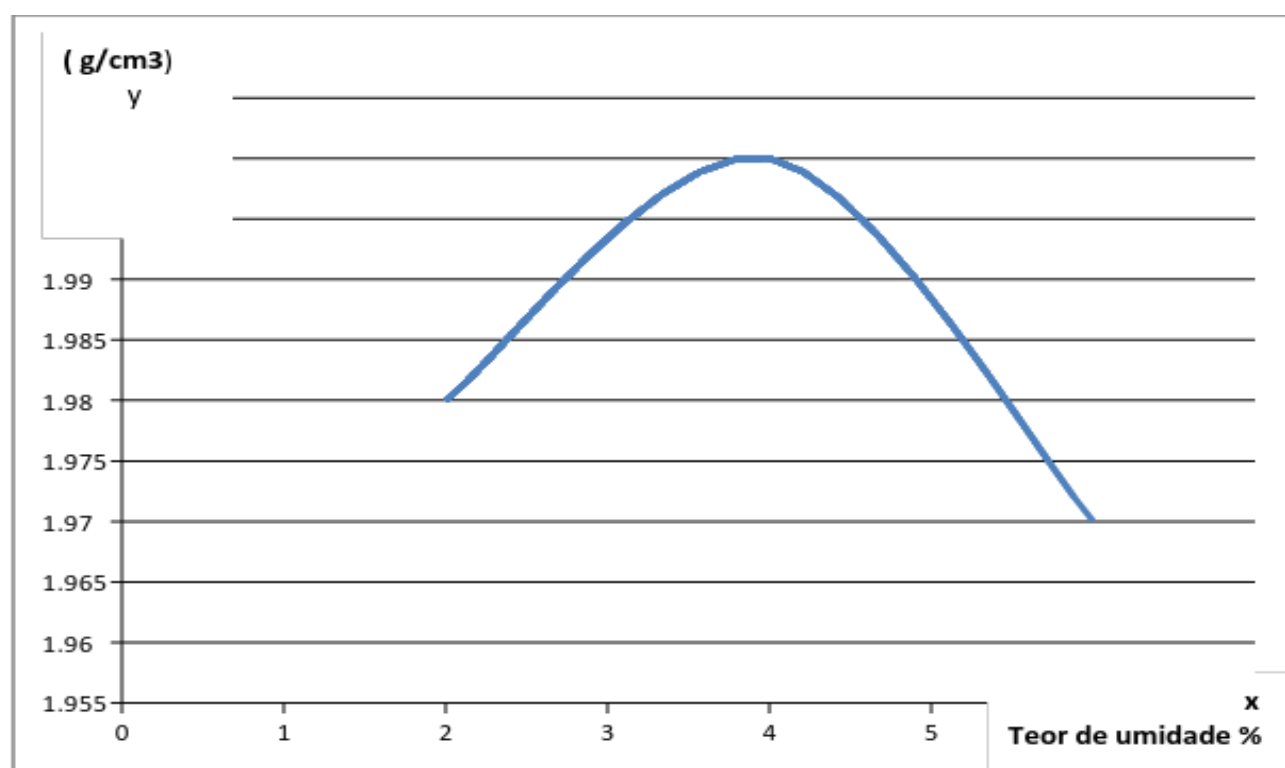

Fonte: Elaborado pelos autores. 


\section{Determinação do CBR}

Conforme a ABNT NBR 15115:2004, agregados reciclados de resíduo sólidos da construção civil - Execução de camadas de pavimentação - Procedimentos, para a realização de base e sub-base de pavimentação, devem seguir os parâmetros apresentados na Tab 3, dados retirados na referida ABNT NBR 15115:2004.

Tabela 3 - Parâmetros de CBR e Expansão - para construção de base e subbase de pavimentação conforme NBR 15115/04

\begin{tabular}{c|c|c|c}
\hline Material para execução & CBR \% & Expansão & Energia de Compactação \\
\hline Reforço de Subleito & 12 & $<1 \%$ & Normal \\
Sub-base & 20 & $<1 \%$ & Intermediária \\
Base & 60 & $<0.5 \%$ & Intermediária \\
\hline
\end{tabular}

Fonte: ABNT (2004b).

Chega-se o resultado final para o CBR determinado, nas proporções de $100 \%$ de RCD e 50\% de RCD que será o maior dos dois valores encontrados correspondentes às penetrações de 2,54 e 5,08 mm conforme a NBR ABNT 9895:1987, tendo os seus valores demonstrados nas tabelas 4 e 5 e calculados conforme as equações 2 e 3 .

Tabela 4 - Caracterização com 100\% de RCD

\begin{tabular}{c|c|c}
\hline Corpos de prova & CBR (\%) & Expansão (\%) \\
\hline 1 & 180 & 0.5 \\
2 & 155 & 2.5 \\
3 & 218 & 1.5 \\
4 & 61 & -12.5 \\
\hline
\end{tabular}

Fonte: Elaborado pelos autores.

Tabela 5 - Caracterização com 50\% RCD

\begin{tabular}{c|c|c}
\hline Corpos de Prova & CBR (\%) & Expansão \% \\
\hline 1 & 160 & 2,5 \\
2 & 17 & -4 \\
3 & 42 & -9 \\
\hline
\end{tabular}

Fonte: Elaborado pelos autores. 
Para atestar a qualidade do material para ser utilizado como suporte na área de pavimentação é necessário destacar os valores de expansão, obtido através do teor de umidade de cada corpo de prova, destacando o valor da expansão correspondente ao teor da umidade ótima das duas proporções de RCD. A importância de conhecer a expansão é devido a problemas patológicos (fissuras) que o pavimento no futuro poderá ocorrer. Conhecendo o grau de expansão/recalque de um pavimento, auxiliará no dimensionamento correto da superestrutura viária, para que os problemas patológicos sejam evitados.

É necessário também obter o valor de CBR ótimo (ou seja, o CBR obtido na umidade ótima), para que se faça a análise completa do material e as devidas comparações, pois é a partir do valor do CBR na umidade ótima, que se obterá a situação crítica em campo.

A partir da análise dos resultados laboratoriais, obtiveram-se os resultados de expansão e CBR, em frente à umidade ótima de cada proporção de RCD (Tab 6).

Tabela 3 - Resultados de expansão e CBR em frente à umidade ótima

\begin{tabular}{|c|c|c|c|c|}
\hline & Corpo de Prova & Umidade \% & CBR \% & Expansão \% \\
\hline $100 \%$ RCD & 3 & 6 & 218 & 1,5 \\
\hline $50 \% \mathrm{RCD}$ & 2 & 4 & 17 & -4 \\
\hline
\end{tabular}

Fonte: Elaborado pelos autores.

Conforme a Norma ABNT 1115:2004 o CBR (corpo de prova 3 - $100 \%$ de RCD) encontrado frente umidade ótima não poderá ser utilizado por apresentar uma expansão superior a $1 \%$, porém, de acordo com ABEDA - 2008 (Associação Brasileira das empresas distribuidoras de asfalto), tal material pode ser utilizado como subleito, por apresentar uma expansão inferior a $2 \%$. Os corpos de provas 1 e 4 não se encontram com o valor próximo da umidade ótima, mas apresentam valores compatíveis com sua utilização conforme indicado pela a norma ABNT 15115:2004, podendo ser utilizados realizando-se o controle da umidade em campo.

Já o corpo de prova 2 (confeccionado com 50\% de RCD e 50\% de solo-argila) encontrado frente a umidade ótima apresentou um resultado compatível para ser utilizado como execução de reforço de subleito . O corpo de prova 3 (confeccionado com $50 \%$ de RCD e 50\% de solo-argila) não se encontra com o valor próximo da 
umidade ótima mas apresenta valores compatíveis para ser utilizado no reforço de subleito e sub-base conforme a norma ABNT 15115:2004, mediante o controle da umidade em campo.

A inclusão dos agregados reciclados no solo para uso de camadas de pavimentos tem apresentado resultados significativos conforme abordado por Jimenez (2011), Motta (2005), Quintanilha (2008) e Amorim (2013). Sendo importante salientar que para ter uma precisão mais efetiva quanto a utilização do RCD para a pavimentação deve-se realizar ensaios com variadas proporções do material de RCD e água.

Quintanilha (2008) realizou os ensaios com RCD coletados por caçamba metálica em canteiro de obras e solo argiloso. Após a realização do ensaio de compactação, os resultados dos corpos de provas que utilizam 100\% de RCD quando comparados com os corpos de provas confeccionados com solo argiloso apresentou resultados positivos. Os corpos de prova de RCD apresentaram resistência, avaliado pelo o ensaio de CBR de $82 \%$ com expansão média nula e de $96 \%$ com expansão em 0,48\%. Os corpos de provas mistos (50\% solo argiloso $+50 \%$ RCD), no entanto, apresentam resultados satisfatórios, mas desempenho estrutural inferior apresentou CBR de 70\% mas expansão maior que os corpos de provas confeccionados apenas com RCD, sendo assim, têm sua utilização delimitada a execução de camadas de reforço de subleito, de sub-base de pavimentos flexíveis e em camadas de baixo fluxo de veículos. Realizando-se uma comparação, verifica-se que o CBR encontrado por Quintilha (2008) apresenta um valor inferior ao CBR encontrado nos ensaios realizados no Laboratório PUC Minas.

Motta (2005) realizou estudos com RCD oriundos de uma usina de britagem de resíduos da construção civil. No ensaio de compactação, observou-se que o teor de umidade ótima foi $11 \%$, acima deste valor o agregado reciclado começa a dar sinal de saturação. Os valores de CBR's e expansão encontrada foram superiores a 75\% para os diferentes tempos de cura analisados, satisfazendo a ABNT NBR 15115:2004. Durante a pesquisa realizada pelo autor, foram observados resultados de uma série de ensaios produzidos por alguns pesquisadores com diversos tipos de agregados reciclados. Observa-se uma diferença nos resultados encontrados, sendo uma das causas principais o tipo e a resistência dos materiais, origem do RCD (sendo ele concreto cerâmico e outros), métodos construtivos, período de realização da obra, tipo de britagem que o 
RCD sofreu energia de compactação, teor de umidade e outros fatores influenciadores. O valor da umidade ótima apresentado por Motta (2005) está muito próximo do valor encontrado nesta pesquisa, comparando-se o valor do CBR encontrado pelo autor e na pesquisa realizada, verifica-se que para o material com 100\% de RCD apresenta-se um valor favorável comparando-se a norma, mas para a sua devida utilização, deve-se atentar para os valores de expansão.

\section{Conclusão}

Diante dos resultados obtidos pode-se concluir que:

a) Quanto ao ensaio de compactação, o teor de umidade ótima para os corpos de provas confeccionados com de $100 \%$ de RCD apresentou a taxa maior (6\%) em comparação com o valor apresentado para os corpos de prova confeccionados com 50\% RCD e 50\% solo-argila (4\%);

b) Quanto ao ensaio de CBR, os valores encontrados com a utilização de $100 \%$ de RCD apresentam-se superiores, já os valores encontrados com a utilização de $50 \%$ RCD e 50\% solo-argila apresentam-se valores inferiores;

c) O CBR (corpo de prova 3) encontrado frente umidade ótima não poderá ser utilizado por apresentar uma expansão superior a 1\%. Os corpos de provas 1 e 4 não tem o valor da umidade ótima, mas apresentam valores compatíveis para serem utilizados na pavimentação, contudo, deve-se realizar o controle da umidade em campo;

d) Já o corpo de prova 2 com $50 \%$ de RCD e 50\% de argila encontrado frente a umidade ótima apresentou um resultado compatível para ser utilizado como execução de reforço de subleito. O corpo de prova 3 não se encontra com o valor próximo da umidade ótima mas apresenta valores compatíveis para ser utilizado para reforço de subleito e sub-base mediante seu controle em campo;

e) A substituição de $50 \%$ do RCD por $50 \%$ de solo-argila produziu um efeito menor sobre a resistência mecânica;

f) A utilização somente de RCD utilizado apresentou-se uma resistência muito maior comparando-se com o solo-argila utilizado;

g) Por se tratar de um material heterogêneo, para avaliar a efetiva substituição dos materiais naturais para o uso do RCD utilizado nesta pesquisa, é necessário realizar novos ensaios com proporções diferentes de adição de água e de RCD; 
h) Quanto à utilização do RCD em obras de pavimentação se torna viável, uma vez que reduz os resíduos dispensados em aterros e em locais clandestinos e contribui favoravelmente com o meio ambiente;

i) De uma maneira geral, pode-se concluir que é possível utilizar os resíduos da construção civil, considerando-se a variabilidade dos mesmos, para confecção de subleito, sub-base e base de pavimentação.

j) O RCD apresentou boas propriedades de resistência e comportamento mecânico que com comportamento mecânico, justificando a sua aplicabilidade na aplicação proposta neste trabalho;

\section{1-Sugestões para trabalhos futuros}

A utilização dos agregados reciclados de RCD como componente de obras de pavimentação é um tema que ainda carece de pesquisa no Brasil e no mundo. Desse modo, algumas sugestões de trabalhos futuros são mencionadas abaixo, com base na linha de pesquisa realizada neste presente trabalho;

a) Realização dos ensaios de Compactação e CBR com novas proporções de adição de água e de RCD para utilização na execução de pavimentação;

b) Confeccionar no mínimo, 03 corpos de provas com cada proporção determinada, para obter resultados mais precisos;

c) Estudos que inclui a coleta de RCD em locais diferentes;

d) Caso o estudo seja realizado com materiais coletados em apenas um local, realizar a coleta dos materiais em diferentes dias;

e) Avaliar os materiais que compõem os RCD's utilizados nas pesquisas;

f) Acompanhar a execução de uma obra de pavimentação para conhecer na prática a utilização do material. 
Referências

AMORIM, Enio Fernandes. Viabilidade técnica econômica de misturas de solo RCD em camadas de base de pavimentos urbanos. Estudo de Caso: Município de Campo Verde. 2014. Disponível em: <http://repositorio.unb.br/bitstream/10482/15206/1/2013_EnioFernandesAmorim.pdf>. Acesso em: 07 mai. 2017.

ÂNGULO, Sérgio Cirelli; ZORDAN, Sérgio Edurado; JOHN, Vanderley Moacyr. Desenvolvimento sustentável e a reciclagem de resíduos na construção civil. São Paulo: SP, 2001. Disponível em: <http://www.pedrasul.com.br/artigos/sustentabilidade.pdf>.Acesso em: 25 abr. 2017.

ASSOCIAÇÂO BRASILEIRA DAS EMPRESAS DISTRIBUIDORAS DE ASFALTO. Manual da Petrobras. 2008. $3^{\text {a }}$ reimpressão. 2010.

ASSOCIAÇÃO BRASILEIRA DE NORMAS TÉCNICAS. NBR 6118 - Projeto de estruturas de concreto - Procedimento. Rio de Janeiro: ABNT, 2004.

ASSOCIAÇÃO BRASILEIRA DE NORMAS TÉCNICAS. NBR $\mathbf{6 4 5 7}$ Compactação e ensaios de caracterização - Amostras de solo. Rio de Janeiro: ABNT, 1986.

ASSOCIAÇÃO BRASILEIRA DE NORMAS TÉCNICAS. NBR 9895 - Índice de Suporte Califórnia (CBR) - Procedimento. Rio de Janeiro: ABNT, 1987.

ASSOCIAÇÃO BRASILEIRA DE NORMAS TÉCNICAS. NBR 15115-Agregados reciclados de resíduos sólidos da construção civil - Execução de camadas de pavimentação - Procedimentos. Rio de Janeiro: ABNT, 2004b. <Disponível em: http://www.areiaovitoria.com.br/download/NBR\%2015115.pdf >.Acesso em: 02 mai. 2017.

ASSOCIAÇÃO BRASILEIRA DE RECICLAGEM DE RESÍDUOS PARA A CONSTRUÇÃO CIVIL E DEMOLIÇÃO. Seminário nacional da reciclagem de RCD. Abrecon, 2015.

JIMENEZ, Alejandra Maria Gomez. Estudo experimental de um resíduo de construção e demolição (RCD) para utilização em pavimentação. 2011.148 f. Dissertação (Mestrado) - Universidade De Brasília, Faculdade De Tecnologia, Departamento De Engenharia Civil e Ambiental, Brasília, 2011. Disponível em: <http://repositorio.unb.br/bitstream/10482/9514/1/2011_Alejandra Maria Gomez Jimenez.pdf>. Acesso em: 11 mar. 2017.

LEITE, Fabiana da Conceição. Comportamento mecânico de agregado reciclado do resíduo sólido da construção civil em camadas de base e sub-base de pavimentos. 2007. 216 f. Dissertação (Mestrado) - Engenharia de Transportes, Escola Politécnica, Universidade de São Paulo, São Paulo, 2007. 
MATTOS, Bernardo Bandeira de Mello. Estudo do reuso, reciclagem, e destinação final dos resíduos da construção civil na cidade do Rio de Janeiro. 2013. $83 \mathrm{f}$. Monografia- Instituto politécnico. Universidade Federal do Rio de Janeiro, UFRJ, Rio de Janeiro, 2013.

MOTTA, Rosangela dos Santos. Estudo laboratorial de agregado reciclado de resíduo sólido da construção civil para aplicação em pavimentação de baixo volume de trafego. 2005. 161 f. Dissertação (Mestrado) - Engenharia de Transportes, Escola Politécnica da Universidade de São Paulo, São Paulo, 2005. Disponível em: <http://www.teses.usp.br/teses/disponiveis/3/3138/tde-19072006-114729/en.php>.

Acesso em: 05 mai. 2017.

MOURA, Rita Fortes. Índice de Suporte Califórnia (ISC) ou CBR (Califórnia). Departamento de estradas de rodagem, Califórnia, Estados Unidos. Disponível em: <http://www.latersolo.com.br/wp-content/uploads/2015/02/4-CAPACIDADE-DESUPORTE-CBR.pdf $>$. Acesso em: 01 mai. 2017.

PINTO, Tarcísio de Paula. Metodologia para a gestão diferenciada de resíduos sólidos da construção urbana. 1999.p.218f. Tese de Doutorado. Universidade de São Paulo,1999.

QUINTANILHA, Frederico Santana. Avaliação de utilização e desempenho de resíduos de construção e demolição em bases e sub-bases de pavimentos flexíveis. 2008. 116 f. Dissertação (Pós-Graduação em Engenharia do Meio Ambiente) Universidade Federal De Goiás, Escola De Engenharia Civil, Goiânia, 2008.

SPADOTTO, Anselmo Jose; ELIAS, Natalia Domingues. Políticas públicas ambientais e responsabilidade da pessoa jurídica. Jus Navigandi, Teresina, v. 16, 2011.

ZORDAN, Sérgio Eduardo. Entulho da indústria da construção civil.Politécnica. Engenharia de Construção Civil. Universidade de São Paulo. 2001. Disponível em: $\langle$ http://www.reciclagem.pcc.usp.br/entulho_ind_ccivil.htm>. Acesso em: $12 \mathrm{abr}$. 2017. 